\title{
The Role of Feedback in Breathing Self-Regulation in Health and Obstructive Sleep Apnea Syndrome Development
}

\author{
Kulchitsky Vladimir*1, Zamaro Alexandra ${ }^{1}$, Zaykina Natalia ${ }^{2}$, Yaromenka Yuliya ${ }^{2}$, Hudny Gennady ${ }^{2}$, Krivenchuk \\ Dmitry $^{1}$, Semenik-Philipovich Tatiana ${ }^{1}$, Koulchitsky Stanislav ${ }^{3}$, Andrianova Tatiana ${ }^{2}$, Dosina Margarita ${ }^{1}$ and \\ Kaliadzich Zhanna ${ }^{4}$ \\ ${ }^{1}$ Institute of Physiology, Belarus
}

${ }^{2}$ Republican Scientific and Practical Center of Otorhinolaryngology, Belarus

${ }^{3}$ University of Liège, Liege, Belgium

${ }^{4}$ State Institution "N.N. Alexandrov National Cancer Centre of Belarus", Republic of Belarus

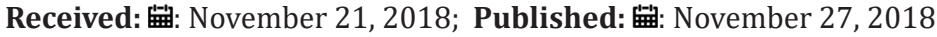

*Corresponding author: Kulchitsky Vladimir, Institute of Physiology, Belarus

\begin{abstract}
Hypothesis on efficiency of feedback from medullary chemoreceptors (MCh) which react to carbon dioxide excess in the organism was tested in patients with obstructive sleep apnea syndrome (OSAS). Attenuation of feedback from MCh to respiratory center was established in $62.5 \%$ of patients with OSAS and $43.8 \%$ of healthy volunteers after "rebreathing" test. Obtained data correspond to significant variability of MCh sensitivity to $\mathrm{CO}_{2}$ content in brain stem in health and disease which is accompanied with increase of $\mathrm{CO}_{2}$ content in the organism. It was concluded that revealed decreased sensitivity of MCh to hypercapnic stimulus in patients with OSAS is one of diagnostic criteria which will allow substantiating reasonability of CPAP (Continuous Positive Airway Pressure) and BiPAP (Biphasic Positive Airway Pressure)-therapy use in patients with OSAS to prevent fatal breathing stop during sleep.
\end{abstract}

Keywords: Medullary Chemoreceptors; Breathing Regulation; Obstructive Sleep Apnea; “Rebreathing” Test; Patients

Abbreviations: BiPAP: Biphasic Positive Airway Pressure; $\mathrm{CO}_{2}$ : Carbon dioxide; CPAP: Continuous Positive Airway Pressure; MCh: Medullary chemoreceptors; OSAS: Obstructive Sleep Apnea Syndrome; $\mathrm{QCO}_{2}$ : Parameter Reflecting Degree of Central Chemoreceptors Functioning

\section{Introduction}

Sudden respiratory arrest during sleep remains socially important problem as it commonly leads to fatal outcome [1,2]. It is quite hard to treat patients with breathing arrest of central genesis. There are a lot of examples and fatal breathing arrest in Ondine's curse (central hypoventilation syndrome) is the one [3]. It is considered that fatal violations of breathing control are determined by peripheral mechanisms in patients with OSAS - in particular, by obstructive events in airways [2,4]. However, doctors noticed that such point of view is not confirmed by the facts of similar frequency of lethal outcomes during sleep in patients with different degrees of OSAS [5]. Therefore, contribution of central mechanisms of breathing regulation to development of fatal outcomes during sleep should be also taken into account - besides peripheral ones [6-9]. Current study was aimed namely at this point.

\section{Rebreathing Test}

40 patients of both sexes aged 22-70 years were examined. 24 patients had obstructive sleep apnea syndrome (13 women and 11 men). 16 healthy volunteers (12 women and 4 men) had no symptoms of OSAS (snoring complaints, airways obstruction, disturbed sleep). Each subject passed "rebreathing" test aimed at determination of central (medullary) brain chemoreceptors sensitivity to carbon dioxide. The device used for test consists of Spirometabolimeter "Spirolan-M" (Saint Petersburg, Russia), modified Douglas bag (12 liters), disposable respiratory circuit and respiratory filters, silicone mask with holding straps, source of $100 \%$ oxygen and personal computer with installed Analyzer-final program (KDI-2018). 
The test was performed in sitting position with arm support. Full-face mask was fixed with holding straps at subject's face. Respiratory circuit was filled with $100 \%$ oxygen. Subject was instructed to perform both inspiration and expiration into closed circuit for 5 minutes or until discomfort appearance. Device automatically registered next parameters of respiratory cycle: test duration ( $T$, sec), inspired volume (Vins, l), expired volume (Vexp, l), breathing frequency per 1 minute (f), end-inspiratory $\mathrm{CO}_{2}$ content $\left(\mathrm{FiCO}_{2}, \%\right)$, end-expiratory $\mathrm{CO}_{2}$ content $\left(\mathrm{EtCO}_{2}, \%\right)$. Subject was asked to remain in sitting position for 10 minutes after the test to restore gas homeostasis.

$\mathrm{QCO}_{2}(\%)$ parameter (degree of central chemoreceptors functioning) was calculated using formula in analyzer-final program:

$$
\begin{aligned}
& \mathrm{QCO}_{2}=\mathrm{e}^{\wedge} \sqrt{ }\left(\left(\sum(\mathrm{i}=0)^{\wedge} \mathrm{n}\left(\left[\operatorname{lnC}\left(\mathrm{Co}_{2}\right)\right]_{\mathrm{i}}-\left[\operatorname{Appr}\left(\left[\operatorname{lnC}\left(\mathrm{Co}_{2}\right)\right]_{\mathrm{i}}\right)^{\wedge} 2\right) / \mathrm{n}\right)\right.\right. \\
& \mathrm{n} \text { - number of respiratory cycles; } \\
& \mathrm{i} \text { - index number of respiratory cycles; } \\
& \text { e - Euler's number (2.71828); } \\
& \mathrm{C} \text { - } \mathrm{CO}_{2} \text { content, \%; }
\end{aligned}
$$

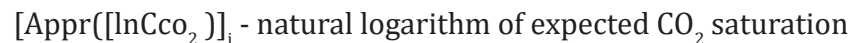
at $\mathrm{i}^{\text {th }}$ moment of time. Regression analysis (least-squares method) was used for statistical data processing.

\section{The Role of Central Mechanisms in Fatal Apnea Develop- ment in Patients with OSAS}

15 patients with OSAS (62.5\%) had $Q=0.16 \pm 0.1 \%$, other 9 had $Q=0.056 \pm 0.02 \%$. Surprisingly, 7 healthy volunteers $(43.8 \%)$ had even higher than patients with OSAS $-0.19 \pm 0.14 \%$. The rest 9 had $Q=0.06 \pm 0.01$. By the way, 6 patients with OSAS (25\%) had low $Q$ values $0.056 \pm 0.02$ ) which in fact corresponded to $Q$ values in patients with OSAS. Significant differences have been revealed when comparing $Q$ values in all patients with OSAS with the ones in healthy volunteers $(p<0.05)$.

What does revealed significance of $Q$ between patients with OSAS and healthy volunteers mean? Increased $Q$ values reflect low sensitivity of central chemoreceptors to carbon dioxide, therefore lowering of respiratory system reactivity to hypercapnic stimulus was established in patients with OSAS compared to healthy volunteers. This is substantiated by the fact of vascular chemoreceptors blockade caused by oxygen excess in inspired air during "rebreathing" [10-14]. Accumulation of carbon dioxide in closed circuit with each expiration is accompanied with activation only those receptors which react on hypercapnic stimulus. In this case different sensitivity $Q$ in healthy volunteers and patients with OSAS reflects the fact of initial difference in chemoreceptor sensitivity between mentioned groups during sleep. It is important that reduction of sensitivity to hypercapnic stimulus in apnea development in such patients will be accompanied with gradually increasing hypercapnic and hypoxic stimuli during nocturnal and daytime sleep. In fact, patient's fate will be sealed in a very short period, because only sensitivity to hypoxic stimulus is preserved during apnea development, but sensitivity to hypercapnic one - is reduced to certain extent. It is recommended to use "rebreathing" technique in clinical practice to reveal functional state of MCh in patients with OSAS and avoid fatality of this Russian roulette-like situation [12,13]. Certified devices for lung ventilation during sleep (CPAP- or BiPAP-therapy) should be used when decreased sensitivity to $\mathrm{CO}_{2}$ is revealed in patients with OSAS.

\section{Conclusion}

Detection of decreased sensitivity of MCh to hypercapnic stimulus in patients with OSAS by "rebreathing" test is one of diagnostic methods which will allow substantiating reasonability of CPAP (Continuous Positive Airway Pressure)- and BiPAP (Biphasic Positive Airway Pressure)-therapy use in patients with OSAS to prevent fatal breathing stop during sleep.

\section{Acknowledgement}

This pooled analysis was funded by means of innovative fund of Brest regional executive committee (2017-2019).

\section{References}

1. Sforza E, Roche F (2016) Chronic intermittent hypoxia and obstructive sleep apnea: An experimental and clinical approach. Hypoxia (Auckl) 4: 99-108.

2. Khattak HK, Hayat F, Pamboukian SV, Hahn HS, Schwartz BP, et al. (2018) Obstructive Sleep Apnea in Heart Failure: Review of Prevalence, Treatment with Continuous Positive Airway Pressure, and Prognosis. Tex Heart Inst J 45(3): 151-161.

3. Perez C (2018) Obstructive sleep apnea syndrome in children. Gen Dent 66(6): 46-50.

4. Semenik TA, Andrianova TD, Alfer IY, Tsishkevich KS, Kaliadzich ZV, et al. (2014) Analysis of contribution of chemosensitive structures to the development of obstructive sleep apnea. Fiziol J 60(3): 50.

5. Drager LF, Lee CH (2018) Treatment of obstructive sleep apnoea as primary or secondary prevention of cardiovascular disease: Where do we stand now? Curr Opin Pulm Med 24(6): 537-542.

6. Schläfke ME, Pokorski M, See WR, Prill RK, Loeschcke HH (1975) Chemosensitive neurons on the ventral medullary surface. Bull Physiopathol Respir (Nancy) 11(2): 277-284.

7. Schlaefke ME, Kille JF, Loeschcke HH (1979) Elimination of central chemosensitivity by coagulation of a bilateral area on the ventral medullary surface in awake cats. Pflugers Arch 378(3): 231-241.

8. Nattie E, Li A (2012) Central chemoreceptors: Locations and functions. Compr Physiol 2(1): 221-254.

9. Koulchitsky SV, Azev OA, Gourine AV, Kulchitsky VA (1994) Capsaicinsensitive area in the ventral surface of the rat medulla. Neurosci Lett 182(2): 129-132.

10. Prabhakar NR, Kumar GK, Peng Y-J (2012) Sympatho-adrenal activation by chronic intermittent hypoxia. J Appl Physiol (1985) 113(8): 13041310 .

11. Ramirez JM, Severs LJ, Ramirez SC, Agosto-Marlin IM (2018) Advances in cellular and integrative control of oxygen homeostasis within the central nervous system. J Physiol 596(15): 3043-3065.

12. Kulchitsky V, Semenik T, Kaliadzich Z, Andrianova T, Tsishkevich K (2014) The analysis of chemosensitive structures contribution to obstructive sleep apnea development. Clin Neurophysiol 125(1): S330-S331.

13. Kaliadzich Z, Semenik T, Riazechkin A, Furmanchuk D, Andrianova T, et al. (2014) Chemoreceptor control of gas homeostasis in patients with obstructive sleep apnea. Act Nerv Super Rediviva 56(3-4): 73-78.

14. Kulchitsky V, Zamaro A, Koulchitsky S (2018) Hypoxia and Hypercapnia: Sensory and Effector Mechanisms. Biomed J Sci \&Tech Res 8(4): 1-3. 
ISSN: 2574-1241

DOI: $10.26717 / B J S T R .2018 .11 .002103$

Kulchitsky Vladimir. Biomed J Sci \& Tech Res

(C) This work is licensed under Creative

Submission Link: https://biomedres.us/submit-manuscript.php

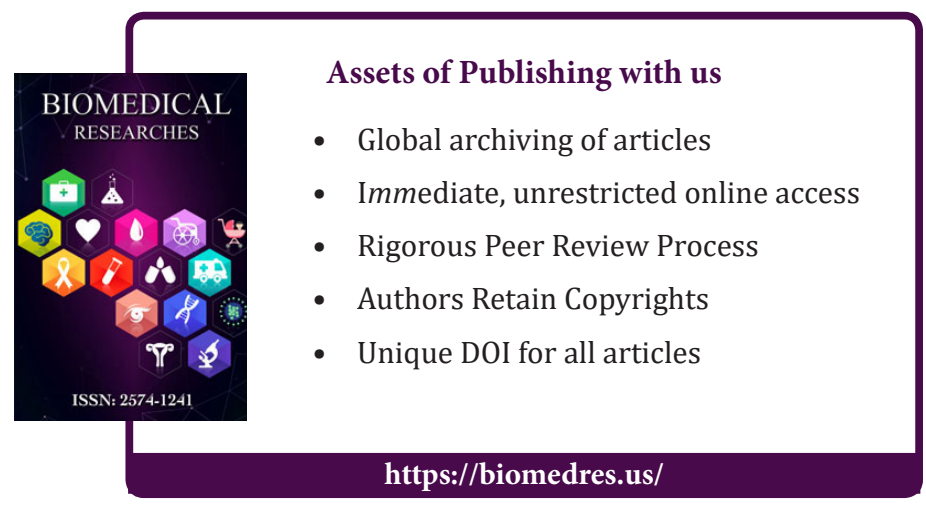

